\title{
Creation of Network Law Doctrine: Theory and Practice
}

\author{
Leonid Viktorovich Goloskokov
}

Russian State Social University, Russia, 129226, Moscow, Vilgelm Pik Street, 4/1

\section{Doi:10.5901/mjss.2015.v6n4p68}

\begin{abstract}
The article deals with the questions of the origin of network law theory, its principles and methods. The object of the research are social relations in a cyberspace, their legal regulation by means of network law and the new opportunities offered by the network in the legal regulation. All this will require creation of a new network theory of law that will explain how to combine such new objects as cyberspace and network with so old a phenomenon as the law. The object includes principles of the theory of network law; principles and methods of informational modernization of law. It was proposed to modernize law by the way of deep integration of informational technologies and law to automatize law-creating and law-realizing processes; there were shown possibilities of application of the theory of network law for the development of legal science branches and the law on the whole.
\end{abstract}

Keywords: network law theory, network law, network state, automation of law implementation, information and communication technologies

\section{Introduction}

\subsection{Introduce the Problem}

Economic and financial crises, as the accelerated development of economy and business necessitates the utilization of new tools of administration, which would enable to control the social relations in the real time mode and not only react to various developments. The contemporary law frequently fails to offer effective means of fast and accurate regulation of the dynamically changing social reality and therefore requires modernization on the basis of the latest achievements in science and technology. The law faces a whole number of problems containing information components: the growing volume, complexity, variability and discrepancy of the legislation. These problems entail the following consequences: 1 ) inefficient regulation of social relations by outdated and imperfect norms of the law; 2) wide-spread legal ignorance and even impossibility of accurate abiding by the law resulting from the complexity and variability of the legislation; 3) shortage of tools providing for the timely adaptation of laws to the quickly changing realities of life.

\subsection{Topicability of the Subject of the Research}

Partial solution of these problems requires radical reconstruction of the legal system, which seems impossible without mutual counter development of law and information-communication technologies (further: ICT). Modernization of law on the basis of the information approach should lead to the formation of network law. Such vector in the development of law is to be set because many states have already started being transformed into "network" states, as for example Russia, in accordance with their conception of creation of an informational society, and while network economy de facto works in many states, there is no network law corresponding to it. Network law is meant to regulate social interactions and relations either directly arising in electronic computer networks, or emerging from using virtual space to some extent, because such social relations are most likely to have their distinct peculiarities.

\subsection{History of investigation of the Subject}

Problems of modernization of law start being discussed in articles, and monographies, where we can find for the first time precise definition of terminology, setting of new problems. As for the informational aspects of law, they are being investigated chiefly on the basis of the new field - informational law. The theoretical basis of the research are the works of specialists in history, jurisprudence, philosophy: (Elon, 2002), (Polyakov, 2003), (Bergel, 2000). The growing role of ICT in different aspects was studied by many authors: (Abramson et al., 1988), (Bell, 1973), (Castells, 1996), (Drucker, 
1993), (Masuda, 1980), (McLuhan, 1989), (Nora and Minc, 1980), (Susskind, 1998), (Zeleznikow and Hunter, 1994).

More recent studies of the elements of the legal doctrines concerned the principles relating to the issues of their formation (Trofimov, 2010), doctrinal understanding of principles of law (Puzikov, 2010), legitimate interests and principles of law (Subochev, 2010), constitutional law principles (Komkova, 2010), international tax law principles (Smirnov, 2010), civil law principles (Vavilin, 2010), labor law principles (Abalduev, 2010).

At the same time there were no theoretical investigations of principles of network law and this fact predetermined the necessity of study of principles of network law (Goloskokov, 2010) and the subject of this research - network law doctrine.

\section{Method}

The new methods of informational modernization of law should consist in strengthening its communicative function, in regulation in the real time mode of social relations, developing in the cyberspace, in automation of law-making and law enforcement, and eventual acceleration of legal proceedings. Such a choice of methods was called forth by the fact that ICT pace of development is very fast, especially when compared with the slow rate of qualitative transformations of the law itself, or its resorting to new technologies. Along with that many fields of human activities can hardly be thought of without the application of information technologies which never fails to give them a new impulse for further development. Hence, in order to adapt the rates of these processes to one another, there arises the necessity for accelerated introduction of new technologies into legal sphere, and the creative process in this field can be construed as follows: moulding of the basics of the theory of the network law; defining principles and methods of the informational updating of law, functions of a network state, network legal tools and legal relations.

Network law is to offer tools for the maximal automation of law-making and law-administration processes by incorporating ICT deeply into legal processes and procedures together with simultaneous information modernization of economy. Among other ways of regulation of social relations there may be creation, maintenance and development of instantly operating network legal communication system between the citizens, the state and its structures.

\subsection{Classification of methods}

The process of modernization of law aimed at creating network legal system can theoretically be divided into modernization of its form and its contents. For modernization of the form we shall offer the following methods: 1) division of normative legal acts according to forms of their presentation into paper and electronic forms with a tendency of gradual transition to the electronic form as the basic one; 2) introduction of a uniform format of the text of laws in both the forms with unification of names of parts of laws, numbering in the electronic form of each symbol, each line of the text and each paragraph; 3) file representation of the text of each law, its segmentation and numbering of segments in an electronic database; application of hyperlinks for the indication of the latent references, decoding of terms, etc.; 4) the placement in the electronic text of each law the database about all its lobbyists and authors with concrete authorship indication of each part of the text (these data should be accessible through a special mode of viewing the document); 5) informational expertise of laws, their simplification and unification of their form of presentation.

Modernization of the contents of law necessitates the application of other methods: 1) deep integration of information technologies and law; 2) automation of the analysis of legal norms and law-making; 3) automation of law implementation; 4) complex automation and visualization of the processes of making and administering laws; 5) legal regulation in the real time mode; 6) transition in legal interrelations from paper technologies to electronic ones and from direct to remote interaction of subjects of law in the networks; 7) modelling and experimenting upon actual subjects; 8) development of legal procedure by creation of the judicial-technological tools providing the automation of routine legal norms and procedures, which should be based on electronic technologies and be initially oriented to networks, including remote ones, with legal interactions between subjects of law in as much automated mode as possible.

\subsection{Application of methods}

It is necessary to seize every opportunity to use as intermediaries in legal network interrelations special information programs (i-robots), capable of carrying out routine legal procedures and processes, and, eventually, of participating in creative processes. We also recommend to realize the idea of an electronic passport of essentially new intent (metapassport) which would allow to provide: 1) creation of a network for legal communications of each person and the state with instantly operating round trip connection; 2) operative legal regulation in the real time mode (for certain kinds of 
legal interrelations); 3) full transition to E-cash.

Metapassport, as we offered (Goloskokov, 2001) should be a kind of integrated into a network terminal (some type of cellular phone-communicator), replacing all other documents and IDs of a person: passport, educational record, driver's license, insurance and medical insurance policies, bank credit cards; etc., it should settle accounts after every transaction; carry out functions of a tax agent which automatically estimates and transfers into the budget taxes from each transaction made by the person, considering his or her status and tax benefits, subsidies, compensations, etc. Actually the information can be stored in departmental databases, and the metapassport would only borrow the data from there in the required volume. We see our task in presenting metapassport in the first place as a legal idea, a pivotal point of the network law, as a tool creating opportunities for network legal communications, and only then as a technological system. Metapassport can simultaneously be of both real and of distributed in space "virtual" design, which a person need not carry about; it can not be lost or completely destroyed. Its essence is not only in transition from a paper passport to an electronic device like the USA passport for travelling abroad with RFID-chips, but also in creation of a complex person identification system (with such parameters as: face, irises, fingerprints, voice and many others) for facilitating the access to guarded objects, full automation of transaction and account settlements (travel fare and transport insurance, retail sale, purchase deals, etc.).

As another part of the technological utilization of the network law system, we offer stationary devices of identification placed in public places and intended for automatic identification and catering of a person (when it is possible) even without showing any physical data carriers like cards, certificates, passports, including those with RFIDchips. Various ways of identification should be used simultaneously in order to provide duplication of safety at both legal and technological levels and avoid dependence of the system on one, even most advanced, technology. In the present article we deliberately refrain from expanding on other most delicate and complicated problems: privacy and observance of human rights. The solution of these problems necessitates additional research and merits a special section in the theory of network law, but the difficulty of the problems, generated by new technologies, should not make us give up the whole idea; the solutions should be sought with the help of the newest technologies, instead of renunciation of computers, networks, ICT and return to the "safe" and "serene" pre-computer epoch.

\section{Transition to Practice}

For the solution of the tasks in question it is necessary to fix in law the following requirements to the legislator: 1) to conduct permanent and systematic search in laws for separate legal norms or their elements, the creation or implementation of which is amenable to automation, and to correct laws in this line; 2) in drafting packages of laws to develop norms, allowing to automate separate, nevertheless interconnected, processes of their legal implementation.

It is possible to offer a partial solution to the problem of variability of the legislation by dividing the norms of law into stable and changeable and placing them in different statutory acts, so that the norms, prone to operative changes, could not, if possible, get into the law which is to show stability. For that it is necessary to present law-making in the form of a structure with the following levels: Long-term, mid-term, short-term and for realization of the latter to create an «independent body», possessing some functions of different branches of authority and able to provide on-line interaction of legal science and administrative practice, in order to promptly create separate legal norms (elements of legal norms, for example, the rates of separate taxes, turnover taxes, the customs duties) by means of which to perform through a network, accurate, timely or anticipatory legal influences on the quickly changing reality, primarily in the sphere of economy.

One of the functions of a network state will be construction of the network law which, due to the application of ICT, should admit the following: 1) increase in the sphere of automated network legal interrelations; 2) increase in the degree of automation of law-making and administering processes which in some cases become semi-automatic or automatic; 3 ) partial delegation of powers of operative legal regulation from legislative level to an independent body with simultaneous automation of law-making and administering processes. Among the functions of a network state will also be the establishing of the independent body which shall carry out: operative legal regulation of swift-flowing economic, financial, tax, customs, migratory and other processes; smooth and continuously effected updating of the economic policy of the state and even solution of such general strategic problems, as management of the national economy under the influence of various international and internal factors.

\section{Principles of Network Law}

As general principles of network law it is possible to offer a principle of its complementary nature to the law-in-force, as 
well as its aiming at the reduction of sanctions, which impart to the law repressive orientation. As special principles of network law it is possible to offer the following: 1) automation of creation and realization of those elements of legal norms which would provide flexibility of operative legal management; 2) gradual shifting of separate elements of legal norms into the sphere of network law where automated regulation in the cyberspace of some legal relations becomes possible; 3 ) simplification of legal norms or their elements, meant to circulate in computer networks, which is necessary for automation of their analysis and application, for their unequivocal understanding and realization; 4) functional simplicity of execution of new laws and other normative legal acts; 5) compulsory nature of the state network registration of all transactions and movements of capitals in the real time mode, transition of all transactions into electronic form; 6 ) maintenance of on-line round-trip legal communication of the subjects of law with the state or its bodies; 7) protection of a person by means of information technologies against the violation of legal norms; 8) equality of responsibility of the citizen and the state; 9 ) the quantity of automatically executed elements of legal norms (or legal norms) should equal quantity of automatically generated elements of legal norms (or legal norms); 10) generation of some elements of legal norms in the electronic form only; 11) arrangement of automated law-executive processes so as to exclude erroneous application of separate legal norms in principle and maximum possible replacement of people by automatic devices in the processes of control; 12) distribution of arbitrators in the network system of on-line arbitration justice with the purpose of providing maximal geographical remoteness of the arbiter from the parties of the on-line process, in order to minimize the influence of local and regional authorities and to reduce possible corruption; 13) optimization in network law of parity between continual and discrete elements with a tendency of moving towards discrete ones, basic for ICT.

\subsection{Practical aspects of using the principles}

Modern understanding of a legal norm suggests that the law be oriented to all the subjects of the state, having equal responsibilities and given equal rights and each norm be designed for repeated application and concern non-concrete addressees of its action (these are continual principles). Peculiar feature of network law is in being oriented to a very great, but nevertheless final group of physical and legal persons, each of them being known personally (discrete principles) as in the network there can be no unregistered subjects of law. At that they are first of all "known" to network system, but in case of necessity which, according to our theory, arises as a rare exception, the person can become known also to a state body inspecting matters concerning the person in question, or eliminating a mistake in the work of network system.

As one of the elements of modernization of law it is possible to offer smooth on-line regulation of economy through taxes by creation of tax-registration complexes established on individual terminals of physical persons and corporations for tracking their financial flows and automatic calculation and exemption of some or even of all the taxes. Transition to a minimum quantity of different kinds of taxes with a sufficient range of tax rates within each tax along with the ability to change these rates smoothly and continuously, which would allow to get the planned budget income, and, if necessary, to correct the income; to obtain an effective system of legal management owing to the use of advantageous regulating functions of taxation; to reach predictability of changes in tax rates; to move on from the control over due payments of taxes to fully automated tax collecting; to refrain from repressive measures and to eliminate tax responsibility.

Partial solution of the problem related to the presumption of knowledge of law is possible in the following ways: complex automation of some law-administering procedures in the sphere of commercial law; drafting of electronic contracts by means of ICT application and on the basis of development and legitimization by the legislator of all possible variants of the contract of the given kind out of which the parties can choose a suitable one in the course of network interaction. To such contracts application of automated procedures of execution and legal proceedings is possible.

Application of ICT is necessary for establishing a network round-trip legal communication between citizens, elected politicians, the state and its bodies which would enable to conduct on-line elections, referenda, recalls of politicians, implementing significant devolution of power through network to people. For the process of enhancing basic principles of democracy it is vital to apply automation of voting procedures by using ICT, personal terminals and voting in a network without visiting polling stations. The network law should offer an essentially new system of monitoring movements of migrants and automatic observance of their abiding by some legal norms. The system envisages: 1) primary prevention of offences and crimes on the part of migrants (for example, non-payment of taxes, staying in the country longer than the established time, etc.); 2) phasing out the opportunities for criminals, terrorists, drug traffickers to freely move about; 3 ) counteraction of criminal money laundering and the financing of terrorism.

The protection of human rights in the system of network law necessitates the automation of realization of those imperative norms of public law (in financial, tax, customs laws) the default of which in the present-day legal system leads to violations of criminal law. In order to protect human rights related to the circulation of one's personal data, the network 
law suggests to automate as much as possible law administering processes for the minimization of access by officials to personal data. Network law can considerably reduce corruption due to transition from traditional "struggle" against it to the creation corruption-free environment. Corruption is possible due to illegal circulation of unregistered cash, but the network law will be built on electronic system of interaction of subjects in which only the registered E-cash will be valid. The same approach is possible for the automation of preventive measures against: terrorism, organized crime, drug dealing, illegal money laundering and other crimes based upon illegal use of unregistered cash.

\section{Results of Implementation of the Theory of Network Law}

Thus in our research has been created the doctrine of network law designed to coordinate social relations taking place in electronic computer networks, or based upon usage of one or another level of virtual space, and social relations in creation, maintenance and development of the system of immediate network legal communications between citizens, state and its structures.

Legal doctrines are usually implemented through hundreds of years (for example, the separation of powers theory by Montesquieu, dated 1748), and most often they are not implemented at all. The implementation of the theory of network law began in Russia 4 years after the defense of author's doctoral thesis in 2006 and publication main propositions of theory. In addition, the author has used an unusual method of spreading the ideas of the theory. Dissertation, books and articles were sent to the President of the Russian Federation, the Government of the Russian Federation, the Parliament of the Russian Federation, all Ministries, The Supreme Court, Supreme Arbitration Court, The Constitutional Court, The Prosecutor General's Office, in all scientific libraries and in all libraries of large public and private universities of Russia. As a result, the main ideas of theory were implemented in the Federal Law \# 210 dated 27 July 2010 "On organization of public and municipal services" and there was a Universal Electronic Card put into use in Russia (in the author's research it was called differently - metapassport). The doctrine of network law led to a global effect, since in the doctrine Russian government found very effective management tools.

Universal Electronic Card has recently started to be introduced in the Russian Federation, but Russia already announced plans to turn it into an electronic passport, the same metapassport, which was proposed by the author.

\section{Discussion}

There were some criticisms of the doctrine of network law. Some professors have expressed doubts about the necessity of the theory of network law. Their main argument was that civil law is sufficient to describe all processes that are available in the network space. They also were convinced that metapassport is the theoretical imagination of the author, and if it is possible, it is not earlier than 100 years. However, the legislator, ministries and departments have seen in the theory of network law a powerful tool of public administration and the main idea of the doctrine of the network law were unusually quickly put into practice. They implemented it in just 4 years. Adoption of the Federal Law \# 210 dated 27 July 2010 "On organization of public and municipal services" led to the creation of Universal Electronic Card as the main technical component of the doctrine, which will provide in the future realization of many other provisions of the theory of network law.

In 2015, the Russian Orthodox Church expressed concern that the Universal Electronic Card can be a tool for total control. However, it can be assumed with confidence that the authorities will continue to implement the project of the Universal Electronic Card.

\section{Conclusions}

The successful implementation of some ideas of the theory of network law inspired the author to develop some ideas of the network society and network state. The result of further studies was the publication of "The Doctrine of a Virtual Network Innovative State". It was published in two well-known Russian law journals: "Public and Private Law" and "New Legal Thought".

These are some ideas of the Doctrine. The Russian government has failed to solve the problem of modernization, innovation in the social and technical fields. The doctrine proposed to remedy the situation to create a network of scientists, professors, engineers, students and other active individuals and professionals. Their task - to collect investments, find the newest ideas and inventions, to begin the process of investment in the latest scientific developments. In the humanitarian sphere, they must find new forms and methods of state-building, to experience them in a micro-state model and propose to implement successful versions in the Russian Federation. The new doctrine 
contains obvious idea that absolute predominance of system based on vertical power is not enough to the successful development of any country. Successful state should have a huge network of people with a lot of horizontal links and personal financial interests. All citizens should take the initiative and participate in the construction and development of their state.

Thus, Russia successfully implements ideas of the theory of network law, because networking methods allow an efficient public administration. Our next scientific idea - is idea of "virtual network innovative state" (a mini-model of the state, destined for innovation, investment and other aims). This is a new tool and method of transformation the world, but this tool is not entirely consistent with the modern Russian paradigm of the vertical power. Possibly, Russian authorities don't need the network of active professionals, united in a large international scientific organization. The prohibitive nature of many recent Russian laws confirms this assumption. Now we face a complex and fascinating task. We ought to continue scientific work in the existing conditions and to obtain practical results.

\section{Acknowledgments}

The theory of network law had emerged thanks to the support of Doctor of jurisprudence, Professor, Honoured scholar of the Russian Federation A.V. Malko. Professor A.V. Malko saw deeper meaning in the theory of network law, when its structure, its methods and principles were not spelled out in detail. The author expresses his deep gratitude to Professor A.V. Malko.

\section{References}

Abalduev, V.A. (2010). Principles of labour law of Russia. Principles of Russian law: general-theoretical and sectoral aspects (pp. 571602). SEl of HPE "Saratov State Law Academy" Publishers: Saratov.

Abramson, J.B., Arterton, F.C. and Orren, G.R. (1988). The Electronic Commonwealth: The Impact of New Media Technologies on Democratic Politics. NY: Basic Books.

Bell, D. (1973). The Coming of Post-Industrial Society. A Venture of Social Forecasting. N.Y., Basic Books.

Bergel, J-L. (1989). Théorie Générale Du Droit. Deuxième édition. Dalloz.

Castells, M. (1996). The Information Age - Economy, Society and Culture. Oxford: Blackwell Publishers. Vol. I: The Rise of the Network Society.

Drucker, P.F. (1993). Post Capitalist Society (1st ed.). N.Y.: Harper Business.

Goloskokov, L.V. (2001). Future Legal Network Technologies. The Computerra. № 3. 2001. pp. $46-47$.

Goloskokov, L.V. (2010). Principles of network law. Principles of Russian law: general-theoretical and sectoral aspects (pp. 330-356). SEl of HPE "Saratov State Law Academy" Publishers: Saratov.

Elon, M. (2002). Jewish law. Saint Petersburg: Yuridichesky Center Press.

Komkova, G.N. Principles of constitutional law of Russia. Principles of Russian law: general-theoretical and sectoral aspects (pp. 369392). SEl of HPE "Saratov State Law Academy" Publishers: Saratov.

Masuda, Y. (1980). The Information Society: as Postindustrial Society. Tokyo: Institute for the Information Society.

McLuhan, M. (1989). The Global Village: Transformations in World Life and Media in the 21st Century. N.Y.: Oxford University Press, $220 \mathrm{p}$.

Nora, S., Minc, A. (1980). The Computerization of Society: A Report to the President of France. Cambridge, Mass.: MIT Press.

Polyakov, A.V. (2003). General Theory of Law. Phenomenologycal-Commucative Approach. A course of lectures. $2^{\text {nd }}$ edition. Saint Petersburg: Yuridichesky Center Press.

Puzikov, R.V. Doctrinal adderstanding of notion, place and role of principles of law in modern legal policy. Principles of Russian law: general-theoretical and sectoral aspects (pp. 86-111). SEl of HPE "Saratov State Law Academy" Publishers: Saratov.

Susskind, R.E. The Future of Law: Facing the Challenges of Information Technology / Published in the United States by Oxford University Press Inc. Revised paperback edition, New York., 1998. 309 p.

Smirnov, D.A. Principles of international tax law. Principles of Russian law: general-theoretical and sectoral aspects (pp. 456-494). SEI of HPE "Saratov State Law Academy" Publishers: Saratov.

Subochev, V.V. legitimate interests and principles of law. Principles of Russian law: general-theoretical and sectoral aspects (pp. 246261). SEI of HPE "Saratov State Law Academy" Publishers: Saratov.

Trofimov, V.V. Legal principles' forming. Principles of Russian law: general-theoretical and sectoral aspects (pp. 52-85). SEI of HPE "Saratov State Law Academy" Publishers: Saratov.

Vavilin, E.A. Principles of civil law. Principles of Russian law: general-theoretical and sectoral aspects (pp. 543-560). SEl of HPE "Saratov State Law Academy" Publishers: Saratov.

Zeleznikow, J., Hunter, D. (1994). Building Intelligent Legal Information Systems: Representation and Reasoning in Law. Deventer; Boston: Kluwer Law and Taxation Publishers. 